\title{
Resection of primary motor cortex tumors: feasibility and surgical outcomes
}

\author{
Stephen T. Magill, MD, PhD, Seunggu J. Han, MD, Jing Li, MD, and Mitchel S. Berger, MD \\ Department of Neurological Surgery, University of California, San Francisco, California
}

OBJECTIVE Brain tumors involving the primary motor cortex are often deemed unresectable due to the potential neurological consequences that result from injury to this region. Nevertheless, we have challenged this dogma for many years and used asleep, as well as awake, intraoperative stimulation mapping to maximize extent of resection. It remains unclear whether these tumors can be resected with acceptable morbidity, whether performing the surgery with the patient awake or asleep impacts extent of resection, and how stimulation mapping influences outcomes.

METHODS A retrospective chart review was performed on the senior author's cohort to identify patients treated between 1998 and 2016 who underwent resection of tumors that were located within the primary motor cortex. Clinical notes, operative reports, and radiographic images were reviewed to identify intraoperative stimulation mapping findings and functional outcomes following tumor resection. Extent of resection was quantified volumetrically. Characteristics of patients were analyzed to identify factors associated with postoperative motor deficits.

RESULTS Forty-nine patients underwent 53 resections of tumors located primarily within the motor cortex. Stimulation mapping was performed in all cases. Positive cortical sites for motor response were identified in $91 \%$ of cases, and subcortical sites in $74 \%$. Awake craniotomy was performed in $65 \%$ of cases, while $35 \%$ were done under general anesthesia. The mean extent of resection was $91 \%$. There was no statistically significant difference in extent of resection in cases done awake compared with those done under general anesthesia. New or worsened postoperative motor deficits occurred in 32 patients $(60 \%)$, and 20 patients $(38 \%)$ had a permanent deficit. Of the permanent deficits, 14 were mild, 4 were moderate, and 2 were severe ( $3.8 \%$ of cases). Decreased intraoperative motor response and diffusion restriction on postoperative MRI were associated with permanent deficit. Awake motor mapping surgery was associated with increased diffusion signal on postoperative MRI.

CONCLUSIONS Resection of tumors from the primary motor cortex is associated with an increased risk of motor deficit, but most of these deficits are transient or mild and have little functional impact. Excellent extent of resection can be achieved with intraoperative stimulation mapping, suggesting that these tumors are indeed amenable to resection and should not be labeled unresectable. Injury to small perforating or en passage blood vessels was the most common cause of infarction that led to moderate or severe deficits. Awake motor mapping was not superior to mapping done under general anesthesia with regard to long-term functional outcome.

https://thejns.org/doi/abs/10.3171/2017.5.JNS163045

KEY WORDS eloquent; rolandic; brain tumor; motor cortex; unresectable; oncology

$\mathrm{T}$ HERE is compelling evidence that increased extent of resection prolongs survival for patients with both low- and high-grade glioma, which has made maximal safe resection one of the primary tenants of glioma surgery. ${ }^{9}$ Multiple techniques can be used intraoperatively to help maximize the extent of resection, including stereotactic neuronavigation with diffusion tensor-based trac- tography, intraoperative MRI, fluorescent tumor markers such as 5-aminolevulinic acid (5-ALA), and stimulation mapping of functional pathways. A recent meta-analysis of data from more than 8000 patients found that intraoperative stimulation mapping reduced the rate of severe neurological deficits by nearly $60 \% .{ }^{5}$ Furthermore, the use of intraoperative stimulation mapping increased the rate of

ABBREVIATIONS ALA = aminolevulinic acid; DTI = diffusion tensor imaging; DWI = diffusion-weighted imaging; TMS = transcranial magnetic stimulation .

SUBMITTED December 3, 2016. ACCEPTED May 30, 2017.

INCLUDE WHEN CITING Published online December 8, 2017; DOI: 10.3171/2017.5.JNS163045. 
gross-total resection from $58 \%$ to $75 \%$, emphasizing its utility in maximizing the extent of resection safely.

Despite all the current advances in glioma surgery, including stimulation mapping, as well as the impact of maximal resection on survival, many neurosurgeons still believe that tumors involving certain areas, such as the primary motor cortex, are unresectable due to the functional significance of this region. It is thought that the risk of developing new or worsened motor deficits outweighs the benefit of surgery. These are valid concerns, and they illustrate the difficulties of achieving onco-functional balance in many cases. ${ }^{6}$ For example, permanent postoperative motor deficits have been reported in up to $20 \%$ of patients undergoing resection of metastases involving the motor cortex or near the corticospinal tract..${ }^{14}$ Even among patients who had motor cortex metastases amenable to radiosurgery, $19 \%$ had worsened motor function after treatment. ${ }^{11}$ Recent data suggest that even in experienced hands, with the aid of intraoperative neuromonitoring and direct cortical stimulation, significant deficits can occur in up to $30 \%$ of patients with motor cortex metastases or gliomas. ${ }^{15}$ For treatment of glioblastomas adjacent to motor cortex, aminolevulinic acid (ALA)-guided resection achieved gross-total resection of the enhancing portion of tumors in $73 \%$ of patients. ${ }^{18}$ Although $30 \%$ of those patients had a new or worsened motor deficit on postoperative Day 1, 3 months postoperatively, only $4 \%$ of patients had a permanent deficit. The better long-term outcomes seen with glioblastoma, an infiltrating tumor, than with brain metastases may be explained by reorganization/relocation of the motor cortex secondary to neural plasticity. ${ }^{8,19}$

Our group has challenged the dogma that tumors within the motor cortex are unresectable. Given their high risk, we have approached these cases with extensive cortical and subcortical intraoperative stimulation mapping. Over the years, we hypothesized that we could push the limits of resection and achieve greater extent of resection with awake motor mapping as opposed to motor mapping done under general anesthesia. Thus, we have performed more motor cortex tumor resections with the patients awake in recent years, and almost exclusively awake since 2012. Here, we review our surgical experience over the last 18 years with tumors involving the motor cortex to answer the following questions. 1) What is the operative morbidity profile in these cases using functional mapping, awake versus asleep? 2) Do the functional outcomes and surgical results differ depending on whether the mapping is done with the patient awake or under general anesthesia? 3) Should resection be favored over biopsy going forward, given that the morbidity is not insignificant?

\section{Methods}

\section{Study Design, Setting, Size, and Patient Group}

This is a retrospective chart review cohort study conducted at a major academic medical center. The study group comprised patients who underwent resection of tumors that invaded the primary motor cortex performed during 1998-2016 by the senior author (M.S.B.). During the study period, the senior author resected 2619 brain tumors. Of those, 1897 were Grade II-IV gliomas, and
1415 of those cases were performed with intraoperative stimulation mapping. Patients were selected from the senior author's case log for review if their case involved the motor cortex or motor mapping had been used. The motor outcomes of the patient were not reviewed prior to patient selection. All patients who underwent surgical resection of tumors that significantly invaded at least $50 \%$ of the anterior-posterior width of the motor cortex (precentral gyrus on axial imaging) were included, which determined the study size. Any patients that were initially screened but did not have tumor involving at least $50 \%$ of width of the actual motor cortex were removed from the cohort. Follow-up was performed via a chart review conducted in 2016. Any patients who did not have sufficient documentation in the electronic medical record, including pre- and postoperative neurological exams, as well as pre- and postoperative MR images that were accessible for review, were excluded. This article was written in accordance with the STROBE (Strengthening the Reporting of Observational Studies in Epidemiology) statement. ${ }^{21}$ The institutional review board at the authors' institution approved this study.

\section{Variables}

Demographic variables included age, sex, and followup duration. Tumor variables included tumor pathology, tumor grade, tumor size, tumor zone/location, and percentage of tumor in the primary motor cortex. The percentage of tumor within the motor cortex was determined by the senior author and is an estimate of roughly how much of the tumor was invading the motor cortex. Larger tumors often had a lower percentage of tumor within the motor cortex, but still invaded more than $50 \%$ of the width of the motor cortex on axial imaging. For tumor zone, the motor cortex was divided into 3 zones (Fig. 1). Zone 1 included the leg/torso cortex, or the medial portion of the motor cortex adjacent to the falx and the sagittal sinus. Zone 2 included the hand cortex, underlying the cerebral convexity and including the hand knob. Zone 3 included the face cortex, which was the anterior and lateral portion of the motor cortex.

Surgical variables included type of anesthesia (general/ asleep vs monitored anesthesia care/awake), the motor mapping techniques used, findings on mapping, and intraoperative changes in neuromonitoring or clinical examination. For motor mapping, variables included whether cortical or subcortical or both types of mapping were done, whether positive sites were found, and what functional muscle groups were found during mapping. All surgical and mapping data were obtained from the operative reports.

Clinical variables collected included presenting symptoms, preoperative motor deficits, postoperative motor deficits, and extent of resection. Motor function/deficits and physical examination findings were obtained from the electronic medical record based on the clinical examination of either the neurosurgery or neurooncology physician's notes. Deficits were categorized as mild, moderate, or severe based on the clinical impact of the deficit. Mild deficits included MRC (Medical Research Council) motor strength Grade 4+, slowed movements, or mild incoordination that had little to no impact on daily living and patient function. Moderate deficits included motor strength 


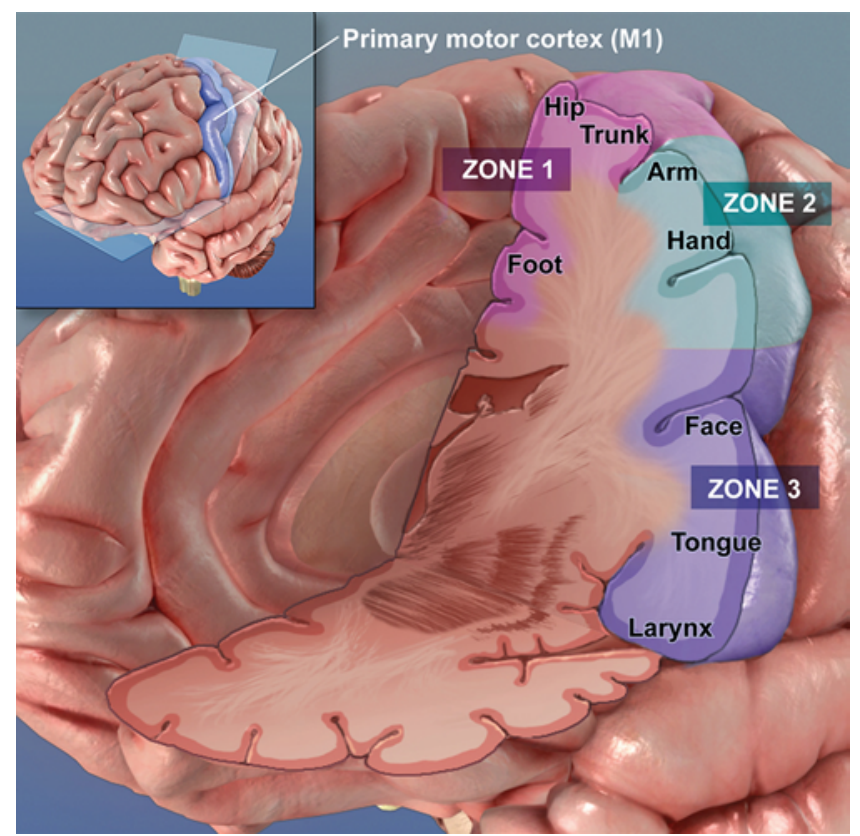

FIG. 1. Schematic of proposed zones of the motor cortex. Zone 1 is medial and involves primarily the leg and trunk cortex. Zone 2 is over the convexity and consists of the hand motor cortex. Zone 3 is lateral and encompasses the face motor cortex. Copyright Kenneth X. Probst. Published with permission. Figure is available in color online only.

Grade 4 or less, long-term weakness with impact on function, or requirement of an assistive device in a patient who was still ambulatory and had basic motor function. Severe deficits included any paralysis, complete loss of function, and development of long-term sequelae from weakness, such as contractures.

For extent of resection calculations, tumor volume was obtained from the stereotactic preoperative MRI and from the postoperative MRI that was performed within 48 hours of resection. We used Brainlab Smartbrush software to measure 3D pre- and postoperative tumor volume. For glioblastoma and contrast-enhancing lesions, the contrastenhancing portion of the tumor, which was the target of resection, was measured. For low-grade, non-contrastenhancing tumors, the FLAIR signal, which indicated the target of resection, was used to calculate the pre- and postoperative tumor volumes. All postoperative scans were reviewed by the authors and evaluated for diffusion restriction. On diffusion-weighted imaging (DWI), the amount of DWI signal was categorized as none, punctate (small focal dots or a thin rim on intermittent edges of the resection cavity), or significant (more than a small punctum or thin rim-i.e., focal areas greater than $1 \mathrm{~cm}$ in thickness around the resection cavity).

\section{Surgery and Mapping}

The senior author performed all resections. Craniotomies were conducted in the usual manner. The Ojemann bipolar stimulator (Integra Neurosciences) was used to perform both direct cortical stimulation mapping and subcortical mapping as previously described..$^{1-3,10,22}$ For cases conducted under general anesthesia, standard neuromoni- toring with electromyography was performed and the anesthesia team and surgical assistants watched for motor responses. For awake motor mapping cases, the patients were awake, alert, and following commands and provided verbal feedback at the time of motor mapping on whether they moved, in addition to the visual monitoring by the anesthesia team and surgical assistants. Both cortical and subcortical stimulation was performed with a 1-msec constant-current square-wave pulse at $60 \mathrm{~Hz}$. Stimulus intensity was typically started at $1 \mathrm{~mA}$ and increased up to 6 $\mathrm{mA}$ for awake cases until a motor response was identified. For asleep cases, stimulus intensity was increased up to $16 \mathrm{~mA}$, in 2-mA increments, until a motor response was identified. The location was considered a negative site if there was no response at 6 or $16 \mathrm{~mA}$, in awake and asleep conditions, respectively. Resection was carried out with the intent of a maximal resection until positive cortical or subcortical mapping sites were reached. At this point, if the patient was under general anesthesia, the resection was stopped. However, if the patient was awake, he or she was asked to move the body part that was positively stimulated. Subsequently, the resection was continued, a millimeter or so at a time, until the patient's function diminished slightly and then the resection was stopped.

\section{Bias}

This is a retrospective study and therefore is limited by selection and observer bias. All patients treated at the authors' institution who had information regarding the variables of interest in the chart were included. No patients were excluded who had information regarding the variables of interest in the chart, thus limiting selection bias. This study is also limited by observer bias in that only information that was recorded in the electronic medical record could be used. Any patient who developed motor deficits that were not recorded, but did occur, could impact the validity of the results.

\section{Statistical Analysis}

All statistical analyses were performed in JMP (version 12.0, SAS Institute Inc.). Demographic data were assembled and analyzed in the standard fashion. For categorical data, chi-square (multiple categories) or Fisher exact (2 categories) tests were reported. Univariate logistic regression was performed and used to calculate odds ratios. Twotailed t-tests were used for comparisons between continuous variables when comparing 2 variables. ANOVA was used for comparisons between continuous variables when comparing 3 or more variables (see Table 8).

\section{Results}

\section{Demographic, Surgical, and Tumor Characteristics}

We identified 49 patients who underwent a total of 53 operations for tumors that involved the primary motor cortex. Four patients had 2 surgeries, and in all 4 of these patients the tumor involved the primary motor cortex in both resections. Motor mapping was performed in all cases. Demographics are included in Table 1. More tumors were resected from the motor cortex in recent years (2012-2016) than in the initial period (1998-2012). Also, 
TABLE 1. Patient demographic and clinical characteristics

\begin{tabular}{|c|c|}
\hline Characteristic & Value \\
\hline Total no. of pts & 49 \\
\hline Total no. of motor mapping surgeries & 53 \\
\hline No. of repeat surgeries & 4 \\
\hline \multicolumn{2}{|l|}{ Sex (no. of pts) } \\
\hline Male & 27 \\
\hline Female & 22 \\
\hline \multicolumn{2}{|l|}{ Age at op (yrs) } \\
\hline Mean & 46.0 \\
\hline Median & 44 \\
\hline Range & $19-75$ \\
\hline \multicolumn{2}{|l|}{ Follow-up (yrs) } \\
\hline Median & 1.00 \\
\hline Mean & 2.00 \\
\hline SD & 2.91 \\
\hline \multicolumn{2}{|l|}{ Tumor grade } \\
\hline 1 & $1(1.9)$ \\
\hline II & $23(43.4)$ \\
\hline III & $14(26.4)$ \\
\hline IV & $15(28.3)$ \\
\hline \multicolumn{2}{|l|}{ Tumor pathology } \\
\hline Oligodendroglioma & $9(17.0)$ \\
\hline Oligoastrocytoma & $5(9.4)$ \\
\hline Astrocytoma & $10(18.9)$ \\
\hline Anaplastic oligoastrocytoma & $5(9.4)$ \\
\hline Anaplastic PXA & $2(3.8)$ \\
\hline Anaplastic astrocytoma & $7(13.2)$ \\
\hline Glioblastoma & $15(28.3)$ \\
\hline \multicolumn{2}{|l|}{ Type of anesthesia } \\
\hline General & $19(35.8)$ \\
\hline Awake/MAC & $34(64.2)$ \\
\hline \multicolumn{2}{|l|}{ Pre-2012* } \\
\hline General & $16(61.5)$ \\
\hline Awake/MAC & $10(38.5)$ \\
\hline \multicolumn{2}{|l|}{ Post-2012† } \\
\hline General & $3(11.1)$ \\
\hline Awake/MAC & $24(88.9)$ \\
\hline \multicolumn{2}{|l|}{ Primary presenting symptom } \\
\hline Seizure & $31(58.5)$ \\
\hline Tumor progression & $16(30.2)$ \\
\hline Weakness & $4(7.5)$ \\
\hline Incidental & $2(3.8)$ \\
\hline Any preop weakness & $16(30.2)$ \\
\hline \multicolumn{2}{|l|}{ Tumor zone } \\
\hline 1 & $12(22.6)$ \\
\hline $1+2$ & $4(7.5)$ \\
\hline 2 & $8(15.1)$ \\
\hline $2+3$ & $1(1.9)$ \\
\hline 3 & $28(52.8)$ \\
\hline
\end{tabular}

CONTINUED IN NEXT COLUMN 》
" CONTINUED FROM PREVIOUS COLUMN

TABLE 1. Patient demographic and clinical characteristics

\begin{tabular}{cc}
\hline \multicolumn{1}{c}{ Characteristic } & \multicolumn{1}{c}{ Value } \\
\hline \multicolumn{2}{c}{ Percentage of tumor in motor cortex } \\
\hline$<50$ & $17(32.1)$ \\
\hline $50-75$ & $8(15.1)$ \\
\hline $75-100$ & $28(52.8)$ \\
\hline
\end{tabular}

$\mathrm{MAC}=$ monitored anesthesia care; pts $=$ patients; $\mathrm{PXA}=$ pleomorphic xanthroastrocytoma.

Values are number of cases (\%) unless otherwise indicated.

* Percentages based on a total of 26 cases.

† Percentages based on a total of 27 cases.

since 2012 nearly all tumors involving the motor cortex were resected using awake motor mapping $(88.9 \%)$, while only $38.5 \%$ were resected with awake motor mapping in the years prior. While $30 \%$ of patients had some preoperative weakness, the most common presenting symptoms prior to surgery were new/worsening seizures or tumor progression. More than half of the tumors $(52.8 \%)$ involved the primary face motor cortex (Zone 3, Fig. 1), followed by leg motor cortex (Zone 1) and then hand motor cortex (Zone 2). Finally, we quantified how much of the motor cortex was involved, with more than half of the tumors (52.8\%) involving more than $75 \%$ of the motor cortex. Example tumors are shown in Fig. 2 (low grade) and Fig. 3 (high grade).

\section{Intraoperative Mapping and Extent of Resection}

Motor mapping with direct electrical stimulation was conducted in all cases included in the series. Stimulationinduced movement was found at cortical sites in $90 \%$ of cases and subcortical sites in 74\% of cases (Table 2). Positive subcortical motor sites were found in all patients who did not have positive cortical motor sites. Hand and face were the most common locations to find stimulationinduced movement. An intraoperative decrease in motor responses occurred in $30 \%$ of cases.

Extent of resection was calculated volumetrically as described in Methods. The mean extent of resection was $91 \%$, with gross-total resection achieved in slightly more than half of cases (Table 3). Nearly $80 \%$ of patients had greater than $90 \%$ extent of resection. Only 10 patients had less than $90 \%$ extent of resection, and only 5 patients had less than $70 \%$ extent of resection. Three patients had less than $50 \%$ of their tumor resected due to positive stimulation sites limiting the resection.

We next tested whether anesthesia type, intraoperative motor findings, or intraoperative deficits influenced extent of resection (Table 4). There was no difference in extent of resection between cases performed under general anesthesia and those performed with awake motor mapping. There also was no difference in extent of resection in cases with or without positive cortical motor mapping, although cases with positive subcortical sites had significantly higher extent of resection. There was no difference in extent of resection in cases with or without a new intraoperative motor deficit. 

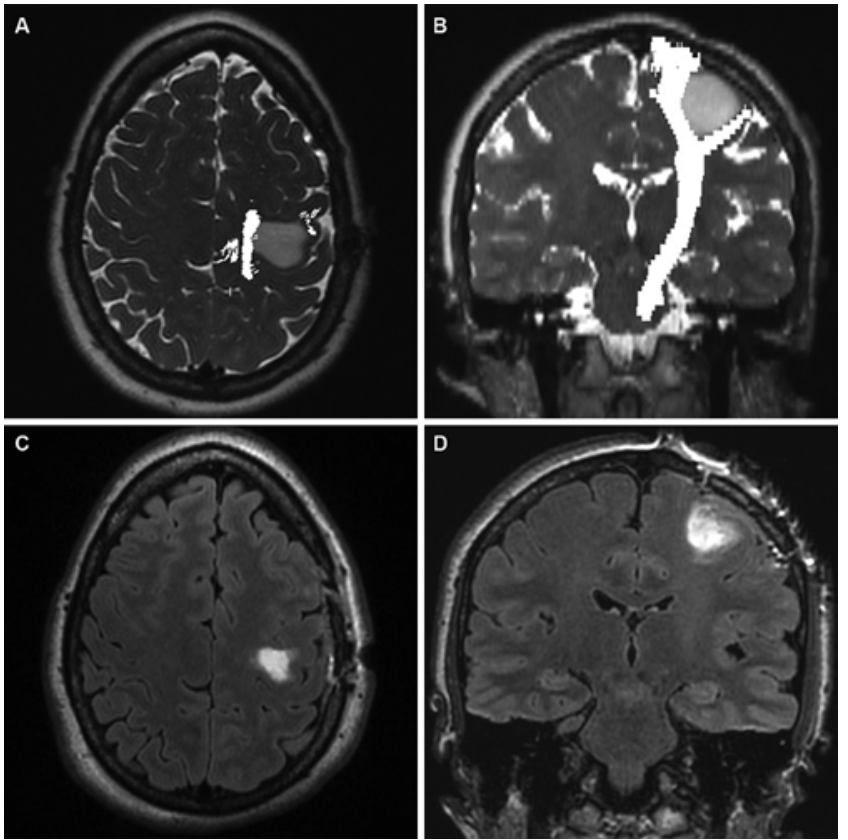

FIG. 2. MR images obtained in a 39-year-old woman who underwent gross-total resection of an anaplastic astrocytoma (Grade III) in the left precentral gyrus in Zone 2 cortex. A and B: Preoperative axial $(A)$ and coronal (B) T2-weighted images with DTI motor tractography showing motor tracts on both sides of the tumor in Zone 2 of the primary motor cortex. C and D: Postoperative axial (C) and coronal (D) T2-weighted FLAIR images showing gross-total resection of the tumor with some residual blood products in the cavity.

\section{Motor Outcomes}

Motor outcomes are detailed in Table 5. Two patients demonstrated improved motor function postoperatively. New or worsened motor deficits occurred after $32(60 \%)$ of 53 operations, and these deficits were permanent in 20 cases (38\%). Permanent deficits were those that persisted at 3 months' follow-up. Permanent deficits were categorized into mild (70\%), moderate (20\%), and severe $(10 \%)$. Notably, only 6 patients had moderate or severe permanent deficits, placing the operative risk for permanent moderate or severe postoperative deficit at $11.3 \%$.

We compared patients with either no deficit or a transient deficit that fully recovered to those with any permanent motor deficits in order to identify risk factors for a permanent motor deficit (Table 6). The presence of an intraoperative decrease in motor function and significant DWI signal intensity were both significantly associated with permanent deficit. Awake motor mapping surgery compared with general anesthesia motor mapping, and the lack of preoperative weakness both trended closely toward but did not achieve statistical significance (defined as $\mathrm{p}<$ 0.05 ). In addition to the variables presented in Table 6 , we also tested to see if there were any significant differences in the presence of a permanent deficit if positive sites were identified during mapping in face versus hand versus arm versus leg, but none were significant.

For patients who developed a permanent deficit, we further analyzed our data to determine whether we could identify any risk factors for moderate or severe deficit com-
TABLE 2. Motor mapping data

\begin{tabular}{cc}
\hline \multicolumn{1}{c}{ Variable } & No. of Cases $(\%)$ \\
\hline Motor mapping performed & 53 \\
\hline Intraop decreased response & $16(30.2)$ \\
\hline Cortical mapping & 53 \\
\hline Stim-induced movement & $48(90.6)$ \\
\hline No motor response & $5(9.4)$ \\
\hline Subcortical mapping & 53 \\
\hline Stim-induced movement & $39(73.6)$ \\
\hline No motor response & $14(26.4)$ \\
\hline Location of positive motor responses & \\
\hline Face & $29(54.7)$ \\
\hline Arm & $17(32.1)$ \\
\hline Hand & $32(60.4)$ \\
\hline Leg & $12(22.6)$ \\
\hline
\end{tabular}

Stim = stimulation.

pared with no or mild deficit only (Table 7). Once again, the presence of DWI signal on postoperative imaging was a strong predictor of a severe postoperative deficit. Interestingly, in contrast to the analysis of any postoperative deficit, including mild deficits, intraoperative decrease in motor responses was not a significant predictor of severe neurological deficit. Finally, volumetric extent of resection
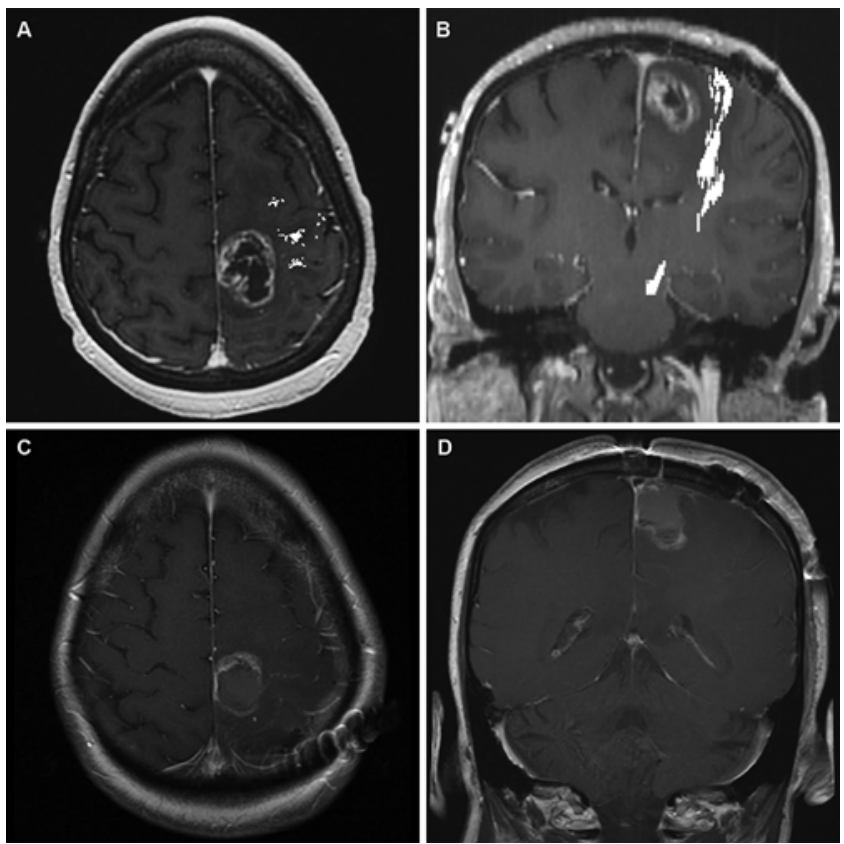

FIG. 3. MR images obtained in a 54-year-old woman who underwent near-total resection of a glioblastoma in the left precentral gyrus in Zones 1 and 2 of the primary motor cortex. A and B: Preoperative axial (A) and coronal (B) T1-weighted postcontrast images with DTI motor tractography showing motor tracts adjacent to the tumor that involve both Zones 1 and 2 of primary motor cortex. C and D: Postoperative axial (C) and coronal (D) T1-weighted postcontrast images showing near-total resection of the tumor with some residual blood products in the cavity. 
TABLE 3. Extent of resection

\begin{tabular}{cc}
\hline \multicolumn{1}{c}{ Variable } & Value \\
\hline Preop tumor vol, $\mathrm{cm}^{3}$ & \\
\hline Mean & 21.6 \\
\hline Median & 12.1 \\
\hline Range & $0.87-73.6$ \\
\hline Postop tumor vol, $\mathrm{cm}^{3}$ & 2.9 \\
\hline Mean & 0 \\
\hline Median & $0-39$ \\
\hline Range & \\
\hline EOR & $27(50.9)$ \\
\hline GTR, no. of cases (\%) & $26(49.1)$ \\
\hline STR, no. of cases (\%) & 91 \\
\hline Mean EOR, $\%$ & 100 \\
\hline Median EOR, $\%$ & $41-100$ \\
\hline Range of EOR, $\%$ & \\
\hline Volumetric EOR, no. of cases (\%) & $27(50.9)$ \\
\hline $100 \%$ & $15(28.3)$ \\
\hline $90-99 \%$ & $1(1.8)$ \\
\hline $80-89 \%$ & $5(9.4)$ \\
\hline $70-79 \%$ & $5(9.4)$ \\
\hline$<70 \%$ &
\end{tabular}

EOR = extent of resection; GTR = gross-total resection; STR = subtotal resection.

trended toward higher percentage (96\% vs 91\%) in patients who developed severe deficits, but the difference did not reach significance.

Given that DWI signal on postoperative imaging was the only factor associated with any postoperative deficit, as well as with severe deficit, we set out to determine whether any of the variables we collected were associated with DWI signal on postoperative MRI (Table 8). Awake sur-

TABLE 4. Extent of resection by anesthesia, mapping, and intraoperative deficit

\begin{tabular}{lcc}
\hline \multicolumn{1}{c}{ Variable } & $\begin{array}{c}\text { Mean Volumetric } \\
\text { EOR }(\%)\end{array}$ & $\begin{array}{c}p \\
\text { Value* }\end{array}$ \\
\hline Anesthesia type & & \\
\hline$\quad$ General & 91.7 & \\
\hline Awake/MAC & 90.8 & 0.83 \\
\hline Mapping & & \\
\hline Cortical stim-induced movement & 90.5 & \\
\hline No cortical motor response & 97.1 & 0.36 \\
\hline Subcortical stim-induced movement & 93.8 & \\
\hline$\quad$ No subcortical motor response & 83.4 & 0.03 \\
\hline Intraop deficit & & \\
\hline$\quad$ New intraop motor deficit & 87.7 & \\
\hline$\quad$ No intraop motor deficit & 92.6 & 0.29 \\
\hline
\end{tabular}

Boldface type indicates statistical significance.

* Based on t-test.
TABLE 5. Motor outcomes in 53 cases in which intraoperative motor mapping was performed

\begin{tabular}{cc}
\hline Outcome & No. of Cases (\%) \\
\hline Improved function postop & $2(3.8)$ \\
\hline New/worsened postop deficit & $32(60.4)$ \\
\hline Transient/short-term deficit & $12(37.5)$ \\
\hline Returned to full strength & $13(40.6)$ \\
\hline Partial recovery & $7(21.9)$ \\
\hline No recovery & $20(37.7)$ \\
\hline Permanent deficit & $14(70)$ \\
\hline Severity of deficit at 3 mos & $4(20)$ \\
\hline Mild (minimal weakness) & $2(10)$ \\
\hline Moderate (impaired function)
\end{tabular}

* Mild deficit was defined as Grade 4+ muscle strength or slight deficit, slowed movements, mild discoordination, etc.; moderate, as Grade 4 or less, long-term weakness with impact on function, requires assistive device, etc.; and severe, as paralysis with complete loss of function and development of contractures over the long term in that limb.

gery, as compared with general anesthesia, was the only factor significantly associated with significant DWI signal. There was a trend toward significance with a decline in intraoperative motor responses being associated with foci of DWI lesions that were larger than $1 \mathrm{~cm}(\mathrm{p}=0.06)$.

\section{Patients With Severe Neurological Deficit}

Finally, we present case-level data for the 6 cases in which the patients had moderate or severe permanent postoperative deficits (Table 9). In 3 of these cases, the tumor was located in the leg motor cortex (Zone 1) and in the other 3 it was located in the face motor cortex (Zone 3). In 4 of the 6 cases the tumors had both cortical and subcortical involvement; in 3 of these cases the tumors were glioblastoma, and in the fourth, the tumor was a Grade II oligodendroglioma. Four of the operations were performed with the patients awake and 2 with the patients under general anesthesia. Positive mapping sites were found in all 6 cases. In 3 of the 6 cases, there was a decline in intraoperative motor responses. In 5 there was a clear significant DWI signal suggestive of an infarct adjacent to the resection cavity, although the smallest such area was only a 6-mm focus (Case 48). In the sixth case, there was no clear infarct and the operation was performed with the patient under general anesthesia, with no decline in intraoperative motor responses.

\section{Discussion \\ Key Results}

Overall, 38\% of the cases in this series resulted in a permanent motor deficit, and $11 \%$ resulted in moderate or severe deficits, which we defined as deficits that impaired function. Only $4 \%$ of cases ( 2 of 53 operations) resulted in a permanent severe deficit. The mean extent of resection was more than $90 \%$ for all patients. There was no difference in morbidity or extent of resection between cases done awake and those done under general anesthesia. Decreased motor responses intraoperatively and significant 
TABLE 6. Comparison of characteristics of patients with no or transient motor deficit versus those with any permanent motor deficit

\begin{tabular}{|c|c|c|c|}
\hline Variable & $\begin{array}{c}\text { No or } \\
\text { Transient } \\
\text { Deficit }\end{array}$ & $\begin{array}{l}\text { Any Perm } \\
\text { Deficit }\end{array}$ & $\begin{array}{l}\text { OR }(95 \% \mathrm{Cl}) \\
\text { or } p \text { Value }\end{array}$ \\
\hline No. of cases & 33 & 20 & \\
\hline Age at op in yrs (mean) & 45.8 & 46.3 & $p=0.89$ \\
\hline \multicolumn{4}{|l|}{ Sex } \\
\hline M & $15(45.5)$ & $13(65.0)$ & 1 (ref) \\
\hline$F$ & $18(54.5)$ & $7(35.0)$ & $0.44(0.14-1.41)$ \\
\hline \multicolumn{4}{|l|}{ Tumor grade } \\
\hline II & $14(42.4)$ & $9(45.0)$ & 1 (ref) \\
\hline III & $9(27.3)$ & $5(25.0)$ & $0.86(0.20-3.39)$ \\
\hline IV & $9(27.3)$ & $6(30.0)$ & $1.04(0.26-3.93)$ \\
\hline \multicolumn{4}{|l|}{ Tumor pathology } \\
\hline Oligodendroglioma & $4(12.1)$ & $5(25.0)$ & 1 (ref) \\
\hline Oligoastrocytoma & $3(9.0)$ & $2(10.0)$ & $0.53(0.04-4.86)$ \\
\hline Astrocytoma & $8(24.2)$ & $2(10.0)$ & $0.20(0.02-1.38)$ \\
\hline $\begin{array}{l}\text { Anaplastic oligoas- } \\
\text { trocytoma }\end{array}$ & $2(6.0)$ & $3(15.0)$ & $1.20(0.13-12.82)$ \\
\hline Anaplastic PXA & $2(6.0)$ & $0(0.0)$ & $-^{*}$ \\
\hline $\begin{array}{l}\text { Anaplastic astrocy- } \\
\text { toma }\end{array}$ & $5(15.1)$ & $2(10.0)$ & $0.32(0.03-4.29)$ \\
\hline Glioblastoma & $9(27.2)$ & $6(30.0)$ & $0.53(0.09-2.82)$ \\
\hline \multicolumn{4}{|l|}{ Type of anesthesia } \\
\hline General & $15(45.4)$ & $4(20.0)$ & 1 (ref) \\
\hline Awake/MAC & $18(54.5)$ & $16(80.0)$ & $3.33(0.97-13.59) \dagger$ \\
\hline \multicolumn{4}{|l|}{ Presenting symptoms } \\
\hline Seizure & $19(57.5)$ & $12(60.0)$ & 1 (ref) \\
\hline Tumor progression & $10(30.0)$ & $6(30.0)$ & $0.95(0.26-3.27)$ \\
\hline Weakness & $3(9.0)$ & $1(5.0)$ & $0.53(0.02-4.68)$ \\
\hline Incidental & $1(3.0)$ & $1(5.0)$ & $-^{*}$ \\
\hline \multicolumn{4}{|l|}{ Preop weakness } \\
\hline Present & $13(39.4)$ & $3(15.0)$ & 1 (ref) \\
\hline Absent & $20(60.6)$ & $17(85.0)$ & $3.68(0.97-18.05) \dagger$ \\
\hline \multicolumn{4}{|l|}{$\begin{array}{l}\text { Intraop decreased } \\
\text { response }\end{array}$} \\
\hline $\begin{array}{c}\text { No change in mo- } \\
\text { tor response }\end{array}$ & $27(81.8)$ & $10(50.0)$ & 1 (ref) \\
\hline $\begin{array}{l}\text { Decreased motor } \\
\text { response }\end{array}$ & $6(18.2)$ & $10(50.0)$ & $4.50(1.33-16.54)$ \\
\hline \multicolumn{4}{|l|}{ Cortical mapping } \\
\hline $\begin{array}{l}\text { Stim-induced move- } \\
\text { ment }\end{array}$ & $31(93.9)$ & $17(85.0)$ & 1 (ref) \\
\hline No motor response & $2(6.1)$ & $3(15.0)$ & $2.74(0.41-22.34)$ \\
\hline \multicolumn{4}{|l|}{ Subcortical mapping } \\
\hline $\begin{array}{l}\text { Stim-induced move- } \\
\text { ment }\end{array}$ & $24(72.7)$ & $15(75.0)$ & 1 (ref) \\
\hline No motor response & $9(27.3)$ & $5(25.0)$ & $0.89(0.23-3.10)$ \\
\hline \multicolumn{4}{|l|}{ Postop DWI } \\
\hline None & $14(42.5)$ & $3(15.0)$ & 1 (ref) \\
\hline
\end{tabular}

CONTINUED IN NEXT COLUMN »
" CONTINUED FROM PREVIOUS COLUMN

TABLE 6. Comparison of characteristics of patients with no or transient motor deficit versus those with any permanent motor deficit

\begin{tabular}{|c|c|c|c|}
\hline Variable & $\begin{array}{l}\text { No or } \\
\text { Transient } \\
\text { Deficit }\end{array}$ & $\begin{array}{l}\text { Any Perm } \\
\text { Deficit }\end{array}$ & $\begin{array}{l}\text { OR }(95 \% \mathrm{Cl}) \\
\text { or } p \text { Value }\end{array}$ \\
\hline \multicolumn{4}{|l|}{ Postop DWI (continued) } \\
\hline Punctate & $17(51.5)$ & $10(50.0)$ & $2.74(0.68-14.05)$ \\
\hline Significant & $2(6.0)$ & $7(35.0)$ & $16.33(2.56-159.05)$ \\
\hline \multicolumn{4}{|l|}{ EOR } \\
\hline GTR & $19(57.6)$ & $8(40.0)$ & 1 (ref) \\
\hline STR & $14(42.4)$ & $12(60.0)$ & $2.04(0.67-6.50)$ \\
\hline Preop tumor vol (mean) & $20.4 \mathrm{~cm}^{3}$ & $23.6 \mathrm{~cm}^{3}$ & $p=0.60$ \\
\hline $\begin{array}{l}\text { Postop tumor vol } \\
\text { (mean) }\end{array}$ & $2.91 \mathrm{~cm}^{3}$ & $2.91 \mathrm{~cm}^{3}$ & $p=1.00$ \\
\hline Volumetric EOR (mean) & $91.8 \%$ & $89.9 \%$ & $p=0.65$ \\
\hline \multicolumn{4}{|l|}{ Tumor zone } \\
\hline 1 & $6(18.2)$ & $6(30.0)$ & 1 (ref) \\
\hline $1+2$ & $4(12.1)$ & $0(0.0)$ & $-^{*}$ \\
\hline 2 & $5(15.2)$ & $3(15.0)$ & $0.60(0.08-3.66)$ \\
\hline $2+3$ & $1(3.0)$ & $0(0.0)$ & $-^{*}$ \\
\hline 3 & $17(51.5)$ & $11(55.0)$ & $0.64(0.16-2.56)$ \\
\hline \multicolumn{4}{|l|}{$\begin{array}{l}\text { Percentage of tumor in } \\
\text { motor cortex }\end{array}$} \\
\hline$<50$ & $10(30.3)$ & $7(35.0)$ & 1 (ref) \\
\hline $50-75$ & $7(21.2)$ & $1(5.0)$ & $0.20(0.01-1.53)$ \\
\hline $75-100$ & $16(48.5)$ & $12(60.0)$ & $1.07(0.32-3.73)$ \\
\hline
\end{tabular}

Perm $=$ permanent; ref $=$ reference .

Data are presented as number of cases (\%) unless otherwise indicated. Bold-

face type indicates statistical significance $(p<0.05)$.

* Unable to compare; sample size too small.

$\dagger p<0.06$.

DWI signal on postoperative MRI were the only significant factors associated with permanent deficits.

\section{Interpretation}

The first goal of our study was to characterize our surgical outcomes, including extent of resection, motor function, and morbidity. The extent of resection was very good, with a mean greater than $90 \%$ and gross-total resection in just over half of all tumors. Careful cortical and subcortical mapping allowed us to maximize the extent of resection. Positive cortical or subcortical motor sites were found in every single case. We resected as aggressively as possible until we found positive motor sites. Interestingly, our extent of resection was significantly less (83\% vs 94\%) when there were no subcortical motor responses found. We achieved greater than $90 \%$ resection in nearly $80 \%$ of our patients; however, we also had $20 \%$ of patients who had less than $70 \%$ resection. Positive motor sites limited the resection in cases with lower extent of resection. The $50 \%$ gross-total resection rate is less than the $75 \%$ for all patients with intraoperative mapping reported previously, ${ }^{5}$ but the cohort in this study was specifically selected for 
TABLE 7. Characteristics of patients with no or mild deficit compared with those with moderate to severe motor deficit on long-term follow-up

\begin{tabular}{|c|c|c|c|}
\hline Characteristic & $\begin{array}{l}\text { No or } \\
\text { Mild } \\
\text { Deficit }\end{array}$ & $\begin{array}{c}\text { Moderate/ } \\
\text { Severe } \\
\text { Deficit }\end{array}$ & $\begin{array}{l}\text { OR }(95 \% \mathrm{Cl}) \\
\text { or } p \text { Value }\end{array}$ \\
\hline No. of cases & 47 & 6 & \\
\hline Age at op in yrs (mean) & 45.9 & 46.7 & $p=0.91$ \\
\hline \multicolumn{4}{|l|}{ Sex } \\
\hline M & $23(48.9)$ & $5(83.3)$ & 1 (ref) \\
\hline $\mathrm{F}$ & $24(51.1)$ & $1(16.7)$ & $0.19(0.01-1.31)$ \\
\hline \multicolumn{4}{|l|}{ Tumor grade } \\
\hline II & $21(44.7)$ & $2(33.3)$ & 1 (ref) \\
\hline III & $13(27.7)$ & $1(16.7)$ & $0.81(0.04-9.27)$ \\
\hline IV & $12(25.6)$ & $3(50.0)$ & $2.63(0.38-22.14)$ \\
\hline \multicolumn{4}{|l|}{ Tumor pathology } \\
\hline Oligodendroglioma & $8(17.0)$ & $1(16.7)$ & 1 (ref) \\
\hline Oligoastrocytoma & $5(10.6)$ & $0(0.0)$ & $-^{*}$ \\
\hline Astrocytoma & $9(19.1)$ & $1(16.7)$ & $0.88(0.03-25.02)$ \\
\hline $\begin{array}{l}\text { Anaplastic oligoastro- } \\
\text { cytoma }\end{array}$ & $4(8.5)$ & $1(16.7)$ & $2.00(0.06-60.5)$ \\
\hline Anaplastic PXA & $2(4.3)$ & $0(0.0)$ & $-^{*}$ \\
\hline Anaplastic astrocytoma & $7(14.9)$ & $0(0.0)$ & $-^{*}$ \\
\hline Glioblastoma & $12(25.5)$ & $3(50.0)$ & $2.00(0.21-44.48)$ \\
\hline \multicolumn{4}{|l|}{ Type of anesthesia } \\
\hline General & $17(36.2)$ & $2(33.3)$ & 1 (ref) \\
\hline Awake/MAC & $30(63.8)$ & $4(66.7)$ & $1.13(0.19-8.79)$ \\
\hline \multicolumn{4}{|l|}{ Presenting symptoms } \\
\hline Seizure & $29(61.7)$ & $2(33.3)$ & 1 (ref) \\
\hline Tumor progression & $13(27.7)$ & $3(50.0)$ & $3.35(0.49-27.79)$ \\
\hline Weakness & $3(6.4)$ & $1(16.7)$ & $4.83(0.19-69.16)$ \\
\hline Incidental & $2(4.3)$ & $0(0.0)$ & $-^{*}$ \\
\hline \multicolumn{4}{|l|}{ Preop weakness } \\
\hline Present & $14(29.8)$ & $2(33.3)$ & 1 (ref) \\
\hline Absent & $33(70.2)$ & $4(66.7)$ & $0.84(0.14-6.63)$ \\
\hline \multicolumn{4}{|l|}{$\begin{array}{l}\text { Intraop decreased } \\
\text { response }\end{array}$} \\
\hline $\begin{array}{l}\text { No change in motor } \\
\text { response }\end{array}$ & $33(70.2)$ & $4(66.7)$ & 1 (ref) \\
\hline $\begin{array}{l}\text { Decreased motor } \\
\text { response }\end{array}$ & $14(29.8)$ & $2(33.3)$ & $1.17(0.15-6.79)$ \\
\hline \multicolumn{4}{|l|}{ Cortical mapping } \\
\hline $\begin{array}{l}\text { Stim-induced move- } \\
\text { ment }\end{array}$ & $44(93.6)$ & $4(66.7)$ & 1 (ref) \\
\hline $\begin{array}{l}\text { No motor response } \\
\text { identified }\end{array}$ & $3(6.4)$ & $2(33.3)$ & $7.33(0.79-59.82)$ \\
\hline \multicolumn{4}{|l|}{ Subcortical mapping } \\
\hline $\begin{array}{l}\text { Stim-induced move- } \\
\text { ment }\end{array}$ & $34(72.3)$ & $5(83.3)$ & 1 (ref) \\
\hline $\begin{array}{l}\text { No motor response } \\
\text { identified }\end{array}$ & $13(27.7)$ & $1(16.7)$ & $0.52(0.03-3.67)$ \\
\hline
\end{tabular}

» CONTINUED FROM PREVIOUS COLUMN

TABLE 7. Characteristics of patients with no or mild deficit compared with those with moderate to severe motor deficit on long-term follow-up

\begin{tabular}{|c|c|c|c|}
\hline Characteristic & $\begin{array}{l}\text { No or } \\
\text { Mild } \\
\text { Deficit }\end{array}$ & $\begin{array}{c}\text { Moderate/ } \\
\text { Severe } \\
\text { Deficit }\end{array}$ & $\begin{array}{l}\text { OR }(95 \% \mathrm{Cl}) \\
\text { or p Value }\end{array}$ \\
\hline \multicolumn{4}{|l|}{ Postop DWI signal } \\
\hline None & $17(36.1)$ & $0(0.0)$ & - $^{*}$ \\
\hline Punctate & $25(53.2)$ & $2(33.3)$ & 1 (ref) \\
\hline Significant & $5(10.7)$ & $4(66.7)$ & $10.00(1.53-88.70)$ \\
\hline \multicolumn{4}{|l|}{ EOR } \\
\hline GTR & $25(53.2)$ & $2(33.3)$ & 1 (ref) \\
\hline STR & $22(46.8)$ & $4(66.7)$ & $2.27(0.40-17.55)$ \\
\hline Preop tumor vol (mean) & $21.7 \mathrm{~cm}^{3}$ & $20.5 \mathrm{~cm}^{3}$ & $p=0.88$ \\
\hline Postop tumor vol (mean) & $3.12 \mathrm{~cm}^{3}$ & $1.23 \mathrm{~cm}^{3}$ & $p=0.15$ \\
\hline Volumetric EOR (mean) & $90.5 \%$ & $96.0 \%$ & $p=0.06$ \\
\hline \multicolumn{4}{|l|}{ Tumor zone } \\
\hline 1 & $9(19.1)$ & $3(50.0)$ & 1 (ref) \\
\hline $1+2$ & $4(8.5)$ & $0(0.0)$ & - $^{*}$ \\
\hline 2 & $8(17.0)$ & $0(0.0)$ & $-^{*}$ \\
\hline $2+3$ & $0(0.0)$ & $1(16.7)$ & - $^{*}$ \\
\hline 3 & $25(53.4)$ & $3(50.0)$ & $0.36(0.06-2.25)$ \\
\hline \multicolumn{4}{|l|}{$\begin{array}{l}\text { Percentage of tumor in } \\
\text { motor cortex }\end{array}$} \\
\hline$<50$ & $15(31.9)$ & $2(33.3)$ & 1 (ref) \\
\hline $50-75$ & $8(17.0)$ & $0(0.0)$ & $-^{*}$ \\
\hline $75-100$ & $24(51.1)$ & $4(66.7)$ & $1.25(0.21-9.82)$ \\
\hline
\end{tabular}

Data are presented as number of cases (\%) unless otherwise indicated. Boldface type indicates statistical significance $(p<0.05)$.

* Unable to compare; sample size too small.

tumors that were located within, and not simply adjacent to, the motor cortex, so the lower rate of gross-total resection is not surprising.

On initial glance, the rate of any new or worsened motor deficit is quite high, at more than $60 \%$, although the rate of any permanent deficits was $38 \%$. Thus, patients undergoing resection of these lesions must be counseled on the high likelihood of new motor deficit or worsened motor function postoperatively, especially during the 1st week as postoperative edema accumulates and then resolves. Reassuringly, however, the majority of these deficits resolve either completely or at least in part. While 6 patients were left with permanent deficits that had a significant functional impact, the deficits were severe in only 2 of these cases. All but one of the moderate/severe deficits had a significant focus of DWI signal that could explain the deficit, reflecting an infarct. Interestingly, only 3 of the 6 patients had intraoperative decreased motor responses, but both patients with severe deficits had intraoperative decreased responses, indicating ischemia. In our experience, these ischemic events can be caused either directly by coagulating an en passage small arteriole or indirectly when there is vasospasm within or adjacent to the resection cavity. Great care must be taken during the resection, and the bipolar cautery is now used sparingly, if it all, to avoid the 
TABLE 8. Characteristics of patients who developed postoperative DWI restriction

\begin{tabular}{|c|c|c|c|c|}
\hline Characteristic & No DWI & Punctate & Significant & $p$ Value \\
\hline No. of cases & 17 & 27 & 9 & \\
\hline Age at op in yrs (mean) & 42.3 & 50.2 & 40.1 & 0.06 \\
\hline \multicolumn{5}{|l|}{ Sex } \\
\hline$M$ & 6 & 18 & 4 & \\
\hline $\mathrm{F}$ & 11 & 9 & 5 & 0.11 \\
\hline \multicolumn{5}{|l|}{ Tumor grade } \\
\hline II & 4 & 13 & 6 & \\
\hline III & 7 & 6 & 1 & \\
\hline IV & 5 & 8 & 2 & 0.28 \\
\hline \multicolumn{5}{|l|}{ Tumor pathology } \\
\hline Oligodendroglioma & 1 & 4 & 4 & \\
\hline Oligoastrocytoma & 2 & 2 & 1 & \\
\hline Astrocytoma & 2 & 7 & 1 & \\
\hline $\begin{array}{l}\text { Anaplastic oligoastrocy- } \\
\text { toma }\end{array}$ & 2 & 2 & 1 & \\
\hline Anaplastic PXA & 2 & 0 & 0 & \\
\hline Anaplastic astrocytoma & 3 & 4 & 0 & \\
\hline Glioblastoma & 5 & 8 & 2 & 0.36 \\
\hline \multicolumn{5}{|l|}{ Type of anesthesia } \\
\hline General & 12 & 6 & 1 & \\
\hline Awake/MAC & 5 & 21 & 8 & 0.002 \\
\hline \multicolumn{5}{|l|}{ Presenting symptoms } \\
\hline Seizure & 10 & 14 & 7 & \\
\hline Tumor progression & 5 & 9 & 2 & \\
\hline Weakness & 1 & 3 & 0 & \\
\hline Incidental & 1 & 1 & 0 & 0.83 \\
\hline \multicolumn{5}{|l|}{ Intraop decreased response } \\
\hline $\begin{array}{l}\text { No change in motor } \\
\text { response }\end{array}$ & 15 & 18 & 4 & \\
\hline $\begin{array}{l}\text { Decreased motor } \\
\text { response }\end{array}$ & 2 & 9 & 5 & 0.06 \\
\hline \multicolumn{5}{|l|}{ Cortical mapping } \\
\hline Stim-induced movement & 0 & 4 & 1 & \\
\hline $\begin{array}{l}\text { No motor response } \\
\text { identified }\end{array}$ & 17 & 23 & 8 & 0.26 \\
\hline \multicolumn{5}{|l|}{ Subcortical mapping } \\
\hline Stim-induced movement & 3 & 9 & 2 & \\
\hline $\begin{array}{l}\text { No motor response } \\
\text { identified }\end{array}$ & 14 & 18 & 7 & 0.49 \\
\hline \multicolumn{5}{|l|}{ EOR } \\
\hline GTR & 10 & 12 & 5 & \\
\hline STR & 7 & 15 & 4 & 0.62 \\
\hline Preop tumor vol (mean), $\mathrm{cm}^{3}$ & 19.0 & 21.7 & 26.0 & 0.69 \\
\hline $\begin{array}{l}\text { Postop tumor vol (mean), } \\
\mathrm{cm}^{3}\end{array}$ & 2.70 & 3.29 & 2.16 & 0.91 \\
\hline Volumetric EOR (mean), \% & 94.6 & 88.8 & 91.4 & 0.47 \\
\hline \multicolumn{5}{|l|}{ Tumor zone } \\
\hline 1 & 6 & 4 & 2 & \\
\hline $1+2$ & 1 & 3 & 0 & \\
\hline
\end{tabular}

» CONTINUED FROM PREVIOUS COLUMN

TABLE 8. Characteristics of patients who developed postoperative DWI restriction

\begin{tabular}{lrrrr}
\hline \multicolumn{1}{c}{ Characteristic } & No DWI & Punctate & Significant & $p$ Value \\
\hline $\begin{array}{l}\text { Tumor zone (continued) } \\
2\end{array}$ & 4 & 3 & 1 & \\
\hline $2+3$ & 1 & 0 & 0 & \\
\hline 3 & 5 & 17 & 6 & 0.34 \\
\hline $\begin{array}{l}\text { Percentage of tumor in mo- } \\
\text { tor cortex }\end{array}$ & & & \\
\hline$\quad<50$ & 5 & 7 & 5 & \\
\hline $50-75$ & 2 & 6 & 0 & \\
\hline $75-100$ & 10 & 14 & 4 & 0.15 \\
\hline
\end{tabular}

Values are numbers of cases unless otherwise indicated. Boldface type indicates statistical significance $(p<0.05)$.

direct injuries. In cases with vasospasm, the spastic artery or arteriole can be seen directly under the microscope and often occurs when resecting a thin cuff of tumor at the margin. When this is seen, especially for a larger artery or arteriole, we administer papaverine on the vessel using a small patty during the procedure and remove it prior to closing the dura. We found that this intervention prevented ischemia in a few cases (Fig. 4).

Other techniques to aid in safe resection of motor cortex tumors have been proposed in addition to intraoperative direct-stimulation mapping. For instance, preoperative transcranial magnetic stimulation (TMS $)^{17}$ has been shown to assist in surgical planning and may be used to augment functional MRI or diffusion tensor imaging (DTI)-based tractography. ${ }^{12}$ In particular, TMS has been reported to be helpful in ruling out functional involvement of the motor cortex and may lead to increased rates of gross-total resection. ${ }^{7}$ Others have shown that TMS mapping that identifies functional tissue in PET-positive lesions correlates with postoperative deficits. ${ }^{13}$ Improved methods of preoperative motor mapping are definitely needed, as the currently used DTI tractography has been shown to be poorly sensitive in identifying motor pathways and should always be augmented by direct cortical stimulation. ${ }^{12}$

The second major goal of our study was to understand whether intraoperative direct-stimulation motor mapping allowed resection of these classically unresectable tumors with acceptable surgical morbidity and whether the method of mapping, either under general anesthesia or awake motor mapping, influenced extent of resection or morbidity. We had hypothesized that we could achieve greater extent of resection and have less morbidity by performing these resections with awake motor mapping as opposed to performing them under general anesthesia. Since 2012, we have almost exclusively done these cases with awake motor mapping, yet there was no difference in extent of resection or motor deficits between mapping awake or under general anesthesia. It is the opinion of the senior author that while either asleep or awake motor mapping is acceptable, awake craniotomies are preferred, especially in patients with any preoperative motor deficits, in order to try to obtain the most detailed cortical and subcortical 
TABLE 9. Cases with permanent moderate or severe deficit

\begin{tabular}{|c|c|c|c|c|c|c|c|c|c|c|c|c|c|}
\hline $\begin{array}{l}\text { Case } \\
\text { No. }\end{array}$ & $\begin{array}{l}\text { Age } \\
\text { (yrs), } \\
\text { Sex }\end{array}$ & $\begin{array}{l}\text { Tumor } \\
\text { Pathology } \\
\text { (grade) }\end{array}$ & Zone & $\begin{array}{l}\text { Cort/ } \\
\text { Subcort }\end{array}$ & $\begin{array}{l}\text { Mod/ } \\
\text { Sev }\end{array}$ & $\begin{array}{l}\text { Preop } \\
\text { Motor } \\
\text { Def }\end{array}$ & Postop Motor Def & $\begin{array}{l}\text { Awake/ } \\
\text { Asleep }\end{array}$ & EOR & $\begin{array}{l}\text { Pos Cort } \\
\text { Mapping }\end{array}$ & $\begin{array}{l}\text { Pos } \\
\text { Subcort } \\
\text { Mapping }\end{array}$ & $\begin{array}{l}\text { Intraop } \\
\text { Motor } \\
\text { Def }\end{array}$ & DWI/Infarct \\
\hline 9 & 37, & $\begin{array}{l}\text { Anaplastic } \\
\text { oligoastro } \\
\text { (III) }\end{array}$ & 1 & Subcort & Sev & None & $\begin{array}{l}\text { Face/lt UE 0; It } \\
\quad \text { LE } 1\end{array}$ & Awake & $100 \%$ & Yes & Yes & Yes & $\begin{array}{l}\text { Infarct deep to } \\
\text { cavity }\end{array}$ \\
\hline 14 & F6, & $\begin{array}{l}\text { Astrocytoma } \\
\text { (II) }\end{array}$ & 1 & Cort & Mod & None & $\begin{array}{l}\text { Rt UE 4; rt LE prox } \\
\text { 2, dist } 0 \text { (recov- } \\
\text { ered, ambulating } \\
\text { w/ AFO) }\end{array}$ & Asleep & $100 \%$ & Yes & Yes & No & $\begin{array}{l}\text { Infarct deep to } \\
\text { cavity }\end{array}$ \\
\hline 21 & 68, & GBM (IV) & 1 & Both & Mod & $\begin{array}{l}\text { Rt UE 4+ } \\
\text { Rt LE 4+ }\end{array}$ & $\begin{array}{l}\text { Rt UE 0-2; rt LE } \\
\text { 0-2 (recovered } \\
\text { to } 4 \mathrm{~s} \text { ) }\end{array}$ & Asleep & $97 \%$ & Yes & Yes & No & $\begin{array}{l}\text { Thin DWI rim } \\
\text { around cavity }\end{array}$ \\
\hline 22 & 29, & $\begin{array}{l}\text { Oligodendro- } \\
\text { glioma (II) }\end{array}$ & 3 & Both & Sev & None & $\begin{array}{l}\text { Lt UE } 0-1 ; \text { It LE } \\
\qquad 1-3\end{array}$ & Awake & $93 \%$ & Yes & No & Yes & $\begin{array}{l}\text { Infarct deep to } \\
\text { cavity }\end{array}$ \\
\hline 32 & 48, & GBM (IV) & 3 & Both & Mod & Rt UE 4+ & $\begin{array}{l}\text { Rt UE 3-4; rt facial } \\
\text { droop }\end{array}$ & Awake & $90 \%$ & Yes & Yes & No & $\begin{array}{l}\text { 2-cm infarct } \\
\text { deep to cavity }\end{array}$ \\
\hline 48 & 62, & GBM (IV) & 3 & Both & Mod & None & Rt UE/rt LE 4 & Awake & $96 \%$ & No & Yes & Yes & $\begin{array}{l}\text { 6-mm infarct } \\
\text { deep to cavity }\end{array}$ \\
\hline
\end{tabular}

AFO = ankle-foot orthosis; cort = cortical; def = deficit; $\mathrm{GBM}=$ glioblastoma; $\mathrm{LE}$ = lower extremity; mod = moderate; oligoastro = oligoastrocytoma; pos = positive; prox = proximal; subcort = subcortical; sev = severe; UE = upper extremity.

map possible. In addition, as discussed in Methods, performing the case with the patient awake allowed additional resection after the positive cortical site was identified until the patient developed a slight deficit. This allowed us to achieve greater extent of resection in each individual case than what would have been achieved if the patient were under general anesthesia. Thus, in more recent years, all patients who were amenable to awake motor mapping, or those patients whose tumor required speech mapping, had their resections performed with awake motor mapping. Nevertheless, given the lack of difference in extent of resection between awake and asleep resections in our data, it seems that direct-stimulation-based motor mapping, regardless of how it is done, is the critical factor to maximally resect these tumors as safely as possible.

New techniques are emerging that may play important roles in making resection of lesions involving the motor cortex safer. In addition to classic direct cortical stimulation, some groups have started doing continuous motor monitoring while resecting tumors adjacent to the corti- cospinal tract with a monopolar stimulator at the tip of the suction device; this holds promise, yet it remains to be seen how it impacts surgical outcomes. ${ }^{16}$ In a recent review, Szelényi and colleagues discussed the use of shorttrain stimulation techniques and how combining those techniques "with continuous MEP monitoring from a strip electrode for both can be used for cortical (anodal stimulation) and subcortical (cathodal stimulation) mapping from a handheld monopolar probe." ${ }^{20}$ Monopolar stimulation is a valid alternative to the $60-\mathrm{Hz}$ bipolar technique and brings with it a lower risk of intraoperative seizures, although the current spread is likely to be greater than with bipolar stimulation. In our practice, we have also started obtaining postoperative MRI with DTI so that if there are postoperative deficits we will be able to evaluate whether the motor fiber tracts were impacted either directly by resection or indirectly by infarction. ${ }^{4}$ Unfortunately, none of our patients with moderate or severe deficits in this series had a postoperative scan with fiber tractography, since this is a relatively new strategy.
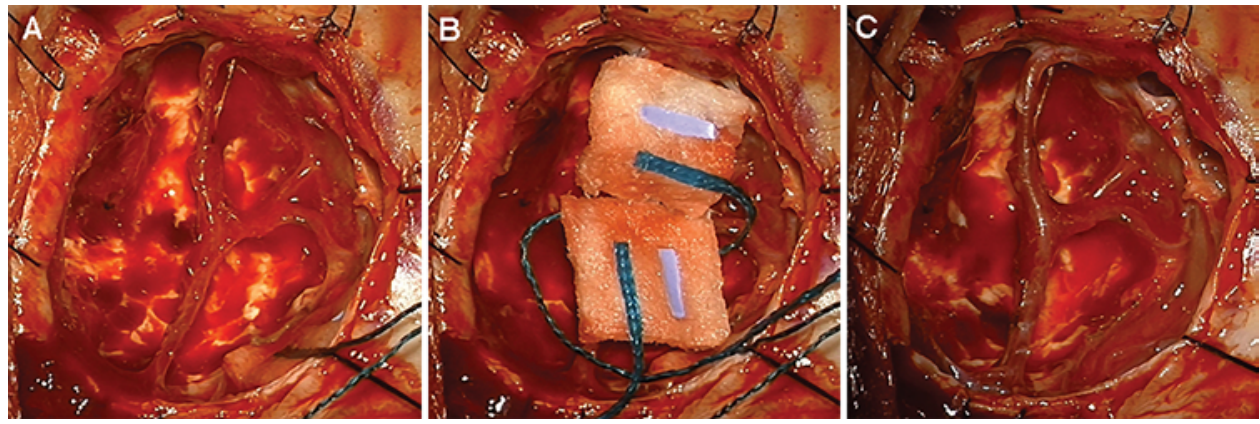

FIG. 4. Case example of spastic artery in the resection cavity and use of papaverine to prevent distal ischemia. A: Spastic artery in resection cavity. B: Papaverine-soaked pledgets on the vessel. The pledgets were placed on the vessel for approximately 5 minutes. C: Subsequent vasodilation. Figure is available in color online only. 


\section{Limitations}

This study is retrospective and is limited by recall bias. We could only evaluate cases with adequate documentation of pre- and postoperative examinations and available imaging. This study is also limited by selection bias, as we only selected cases that on review of imaging were deemed to involve tumors occupying more than $50 \%$ of the thickness of the motor cortex. Patients who were not referred to us because their tumors were deemed unresectable also would not have been included in the study. Finally, the severity of the deficit and functional impact was assessed based on review of physician notes, and the surgeon/physician assessment, and it is possible that objective strength testing by an independent evaluator may have revealed subtle deficits that were missed or deficits that had greater impact on the patient's life than determined by the evaluating physician.

\section{Generalizability}

These results are those of a specialized surgeon with a high-volume primary brain tumor practice, working with a team of anesthesia and neuromonitoring specialists focused on these types of cases, and thus may not be generalizable to all surgeons or institutions. Nevertheless, the principles and techniques of direct intraoperative stimulation motor mapping should be generalizable to other experienced tumor neurosurgeons and should be widely applied. Furthermore, the importance of not deeming tumors unresectable, simply because of their location in the motor strip, is widely generalizable, and all patients with lesions in eloquent cortex should only be resected with the aid of stimulation mapping.

\section{Conclusions}

Resection of tumors from the primary motor cortex is associated with a risk of postoperative motor deficits, but most of these deficits are transient or mild and have little functional impact, with only 2 cases in this series in which the impact was severe. Excellent extent of resection can be achieved with intraoperative stimulation mapping, suggesting that these tumors are indeed amenable to resection and should not be labeled unresectable. Injury to small perforating or en passage blood vessels was the most common cause of infarction that caused moderate or severe deficits. Thus, bipolar cautery should be avoided and intraoperative use of papaverine should be applied to visible arteries and arterioles intermittently during the course of surgery. Awake motor mapping was not superior to mapping done under general anesthesia in terms of enhancing extent of resection or minimizing deficits. It is unclear whether intraoperative stimulation or the use of continuous motor evoked potentials could reduce the permanent morbidity further when removing gliomas from the motor cortex. Based on this study, stimulation mapping of cortical and subcortical motor function is essential to maximize resection of motor cortex tumors with an acceptable morbidity profile.

\section{Acknowledgments}

We would like to thank Kenneth X. Probst for turning our rough sketches into the excellent illustration in Fig. 1.

\section{References}

1. Berger MS, Cohen WA, Ojemann GA: Correlation of motor cortex brain mapping data with magnetic resonance imaging. J Neurosurg 72:383-387, 1990

2. Berger MS, Ojemann GA: Intraoperative brain mapping techniques in neuro-oncology. Stereotact Funct Neurosurg 58:153-161, 1992

3. Berger MS, Ojemann GA, Lettich E: Neurophysiological monitoring during astrocytoma surgery. Neurosurg Clin $\mathbf{N}$ Am 1:65-80, 1990

4. Caverzasi E, Hervey-Jumper SL, Jordan KM, Lobach IV, Li $\mathrm{J}$, Panara V, et al: Identifying preoperative language tracts and predicting postoperative functional recovery using HARDI q-ball fiber tractography in patients with gliomas. $\mathbf{J}$ Neurosurg 125:33-45, 2016

5. De Witt Hamer PC, Robles SG, Zwinderman AH, Duffau H, Berger MS: Impact of intraoperative stimulation brain mapping on glioma surgery outcome: a meta-analysis. J Clin Oncol 30:2559-2565, 2012

6. Duffau H, Mandonnet E: The "onco-functional balance" in surgery for diffuse low-grade glioma: integrating the extent of resection with quality of life. Acta Neurochir (Wien) 155:951-957, 2013

7. Frey D, Schilt S, Strack V, Zdunczyk A, Rösler J, Niraula B, et al: Navigated transcranial magnetic stimulation improves the treatment outcome in patients with brain tumors in motor eloquent locations. Neuro Oncol 16:1365-1372, 2014

8. Hayashi Y, Nakada M, Kinoshita M, Hamada J: Functional reorganization in the patient with progressing glioma of the pure primary motor cortex: a case report with special reference to the topographic central sulcus defined by somatosensory-evoked potential. World Neurosurg 82:536.e1-536.e4, 2014

9. Hervey-Jumper SL, Berger MS: Maximizing safe resection of low- and high-grade glioma. J Neurooncol 130:269-282, 2016

10. Keles GE, Lundin DA, Lamborn KR, Chang EF, Ojemann G, Berger MS: Intraoperative subcortical stimulation mapping for hemispherical perirolandic gliomas located within or adjacent to the descending motor pathways: evaluation of morbidity and assessment of functional outcome in 294 patients. J Neurosurg 100:369-375, 2004

11. Luther N, Kondziolka D, Kano H, Mousavi SH, Flickinger JC, Lunsford LD: Motor function after stereotactic radiosurgery for brain metastases in the region of the motor cortex. $\mathbf{J}$ Neurosurg 119:683-688, 2013

12. Mandelli ML, Berger MS, Bucci M, Berman JI, Amirbekian B, Henry RG: Quantifying accuracy and precision of diffusion MR tractography of the corticospinal tract in brain tumors. J Neurosurg 121:349-358, 2014

13. Neuschmelting V, Weiss Lucas C, Stoffels G, Oros-Peusquens AM, Lockau H, Shah NJ, et al: Multimodal imaging in malignant brain tumors: enhancing the preoperative risk evaluation for motor deficits with a combined hybrid MRIPET and navigated transcranial magnetic stimulation approach. AJNR Am J Neuroradiol 37:266-273, 2016

14. Obermueller T, Schaeffner M, Gerhardt J, Meyer B, Ringel F, Krieg SM: Risks of postoperative paresis in motor eloquently and non-eloquently located brain metastases. BMC Cancer 14:21, 2014

15. Obermueller T, Schaeffner M, Shiban E, Droese D, Negwer C, Meyer B, et al: Intraoperative neuromonitoring for function-guided resection differs for supratentorial motor eloquent gliomas and metastases. BMC Neurol 15:211, 2015

16. Raabe A, Beck J, Schucht P, Seidel K: Continuous dynamic mapping of the corticospinal tract during surgery of motor eloquent brain tumors: evaluation of a new method. J Neurosurg 120:1015-1024, 2014

17. Rizzo V, Terranova C, Conti A, Germanò A, Alafaci C, Raffa 
G, et al: Preoperative functional mapping for rolandic brain tumor surgery. Neurosci Lett 583:136-141, 2014

18. Schucht P, Seidel K, Beck J, Murek M, Jilch A, Wiest R, et al: Intraoperative monopolar mapping during 5-ALA-guided resections of glioblastomas adjacent to motor eloquent areas: evaluation of resection rates and neurological outcome. Neurosurg Focus 37(6):E16, 2014

19. Southwell DG, Hervey-Jumper SL, Perry DW, Berger MS: Intraoperative mapping during repeat awake craniotomy reveals the functional plasticity of adult cortex. J Neurosurg 124:1460-1469, 2016

20. Szelényi A, Bello L, Duffau H, Fava E, Feigl GC, Galanda $\mathrm{M}$, et al: Intraoperative electrical stimulation in awake craniotomy: methodological aspects of current practice. Neurosurg Focus 28(2):E7, 2010

21. von Elm E, Altman DG, Egger M, Pocock SJ, Gøtzsche PC, Vandenbroucke JP: The Strengthening the Reporting of Observational Studies in Epidemiology (STROBE) statement: guidelines for reporting observational studies. PLoS Med 4:e296, 2007

22. Yingling CD, Ojemann S, Dodson B, Harrington MJ, Berger MS: Identification of motor pathways during tumor surgery facilitated by multichannel electromyographic recording. J Neurosurg 91:922-927, 1999

\section{Disclosures}

The authors report no conflict of interest concerning the materials or methods used in this study or the findings specified in this paper.

\section{Author Contributions}

Conception and design: Berger, Magill. Acquisition of data: Berger, Magill, Li. Analysis and interpretation of data: Berger, Magill, Han. Drafting the article: Berger, Magill, Han. Critically revising the article: Berger, Magill, Han. Reviewed submitted version of manuscript: Berger, Magill, Han. Statistical analysis: Magill, Han. Administrative/technical/material support: Magill. Study supervision: Berger.

\section{Correspondence}

Mitchel S. Berger, Department of Neurological Surgery, University of California, San Francisco, 505 Parnassus Ave., M779, San Francisco, CA 94143-0112. email: mitchel.berger@ucsf.edu. 